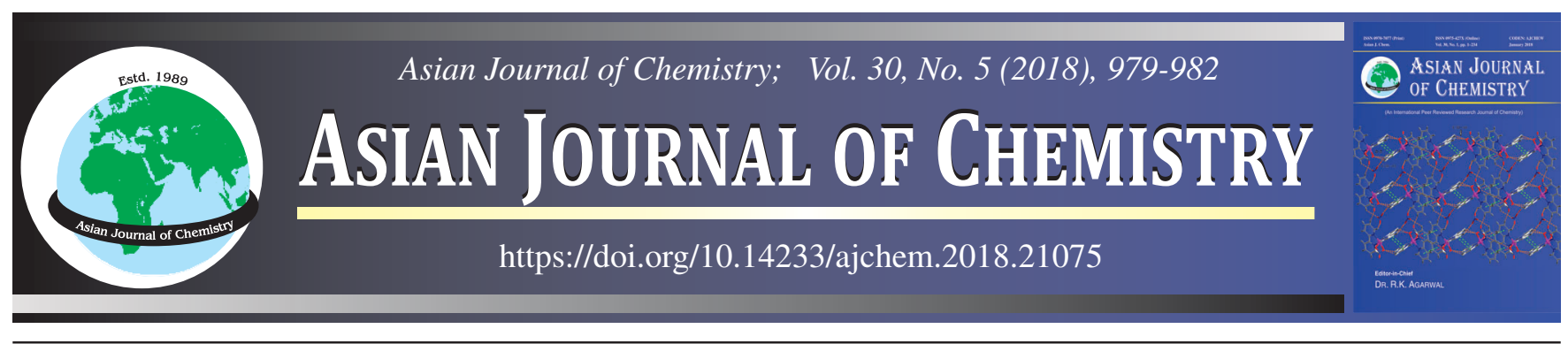

\title{
Synthesis and Characterization of Complexes of Pd(II) and Pt(II) with Steryl Derivatives of 2-Alkylbenzimidazole
}

\author{
RAJESH Kumar ${ }^{1}$ and MADHU Balä,*
}

${ }^{1}$ Department of Chemistry, Ranchi University, Ranchi-834 008, India

${ }^{2}$ Department of Chemistry, National Institute of Technology Patna, Ashok Rajpath, Mahendru, Patna-800005, India

*Corresponding author: E-mail: madhub252@gmail.com

Received: 5 October 2017;

Accepted: 26 November 2017;

Published online: 29 March 2018;

AJC-18824

Dichloro and dithiocyanto complexes of $\mathrm{Pd}(\mathrm{II})$ and $\mathrm{Pt}(\mathrm{II})$ with steryl derivatives of 2-alkyl benzimidazole $(\mathrm{L})$ of composition $\mathrm{PdLX}$ ( $\mathrm{L}=$ Bzmbl, Bzebl, Bzprbl and Bzpmbt $\mathrm{X}=\mathrm{Cl}^{-}$or $\left.\mathrm{NCS}^{-}\right)$and $\mathrm{PtL}_{2} \mathrm{X}_{2}\left(\mathrm{X}=\mathrm{Cl}^{-}\right.$or $\mathrm{SCN}^{-}$and $\mathrm{L}=\mathrm{Bzmbl}$, Bzebl, Bzprbl or Bzpmbl) where Bzmbl = 1-(1H-benzimidazol-2-yl)methylbenzylidene, Bzebt = 1-(1H-benzimidazol-2-yl)ethylbenzylidene, Bzprbl = 1-(1H-benzimidazol-2yl)propylbenzylidene, bzpmbl = 1-(1H-benzimidazol-2-yl)phenyl-1-methylbenzylidene have been synthesized and characterized by electrical conductance, UV and infrared spectral studies. The IR spectral studies of $\mathrm{PdLCl}_{2}$ complexes showed shifting of steryl group $v(\mathrm{CH}=\mathrm{CH})$ vibrations to lower frequencies indicating involvement of $\mathrm{HC}=\mathrm{CH}$ double bond to $\mathrm{Pd}(\mathrm{II})$. The UV and magnetic moment value of $\mathrm{Pd}(\mathrm{II})$ and $\mathrm{Pt}(\mathrm{II})$ complexes are consistent with square planar structure.

Keywords: Palladium(II), Platinum(II), Benzimidazolylsteryl complexes.

\section{INTRODUCTION}

Metal complexes based on flexible bis(imidazole) and bis(triazole) ligands containing different functional groups has been characterized crystallographically $[1,2]$. However, bis(benzimidazole) ligands, a class of aromatic $\mathrm{N}$-donor organic linkers, exhibited important physiological and pharmacological activity due to the presence of substitutions at the 1,2 and 5 positions $[3,4]$ and also some applications are found in the treatment of several diseases including epilepsy, diabetes and infertility $[5,6]$. The metal complexes of benzimidazole derivatives have been studied extensively [7-12]. From the literature survey, it is found that complexes of $\mathrm{Pd}(\mathrm{II})$ and $\mathrm{Pt}(\mathrm{II})$ with steryl derivatives of 2-alkylbenzimidazoles have little been studied [13]. The benzimidazole derivatives have immense medicinal utility [6] which aroused interest towards the studies of their metal complexes.

In present paper, we reported the synthesis and characterization of the complexes of $\mathrm{Pd}(\mathrm{II})$ and $\mathrm{Pt}(\mathrm{II})$ with four steryl derivatives of alkyl benzimidazoles namely 1-(1H-benzimidazol-2-yl)methylbenzylidene (Bzmbl), 1-(1H-benzimidazol2-yl)ethylbenzylidene (Bzebl), 1-(1H-benzimidazol-2-yl)-1phenylmethylbenzylidene (Bzpmbl) and 1-(1H-benzimidazol2-yl)propylbenzylidene (Bzprbl) (Fig. 1). These ligands coordinated with $\mathrm{Pd}(\mathrm{II})$ and $\mathrm{Pt}(\mathrm{II})$ as potent nitrogen donor ligand. In some cases, it appears that steryl double bond $(-\mathrm{C}=\mathrm{CH})$ is also involved in bonding with $\mathrm{Pd}(\mathrm{II})$.

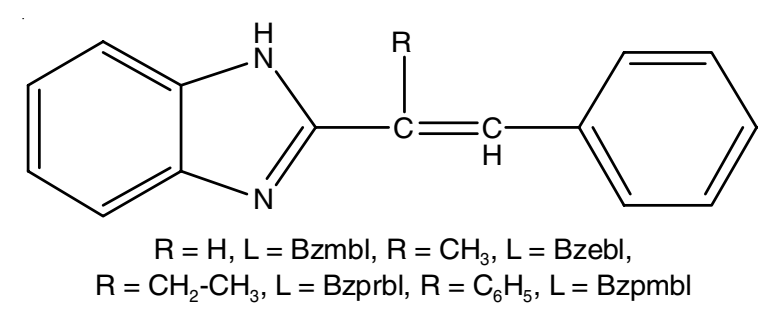

Fig. 1. Structure of steryl derivatives of alkyl benzimidazole ligand

\section{EXPERIMENTAL}

The stock solutions of $\mathrm{PdCl}_{2}$ and $\mathrm{PtCl}_{2}$ were prepared by dissolving $1 \mathrm{~g}$ of palladium(II) chloride in $10 \mathrm{~mL}$ hot water containing $1 \mathrm{~mL}(4 \mathrm{~N}) \mathrm{HCl}$. The clear solution was diluted with ethyl alcohol to $50 \mathrm{~mL}$ to get millimolar solution of $\mathrm{PdCl}_{2}$. Platinum (II) chloride ( $1 \mathrm{~g}$ ) was dissolved in $40 \mathrm{~mL}$ aqueous ethanol to get $1 \mathrm{mmol}$ stock solution.

Synthesis of [PdLCl $]$ ( $\mathbf{L}=\mathbf{B z m b l}$, Bzebl, Bzpmbl or Bzprbl): About $5 \mathrm{mmol}$ of ethanolic solution of the corresponding ligand $(10 \mathrm{~mL})$ was taken in a round bottom flask and treated with $5 \mathrm{mmol}$ of palladium(II) chloride solution and heated on a steam bath for $0.5 \mathrm{~h}$ and concentrated to half of its bulk when brownish yellow precipitate separated. The product was filtered, washed with cold ethanol and dried in a desiccator over $\mathrm{CaCl}_{2}$. 
Synthesis of [PdL(NCS $\left.)_{2}\right]$ : About $0.05 \mathrm{~g}$ of synthesized $\mathrm{PdLCl}_{2}$ was suspended in $20 \mathrm{~mL}$ ethanol and treated with $0.1 \mathrm{~g}$ of potassium thiocyanate and refluxed on a steam bath for $1 \mathrm{~h}$ when orange yellow solution was formed. The solution was concentrated to $5 \mathrm{~mL}$ till orange yellow dithiocyanato complex separated. The product was filtered, washed with few drops of water to remove separated $\mathrm{KCl}$ and excess of KCNS. The residue was finally washed with aqueous ethanol and dried over $\mathrm{CaCl}_{2}$.

Synthesis of $\mathrm{PdL}_{2} \mathrm{Cl}_{\mathbf{2}}(\mathrm{L}=\mathrm{Bzmbl}$, Bzebl and Bzprbl): About $10 \mathrm{mmol}$ of ethanolic solution of the corresponding ligand was treated with $5 \mathrm{mmol}$ solution of Pd (II) chloride and stirred for a few min when cream yellow product separated on concentration. The products were collected on a filter washed with cold aqueous ethanol and dried over $\mathrm{CaCl}_{2}$ in a desiccator.

Synthesis of $\left[\mathrm{PtL}_{2} \mathrm{X}_{2}\right]\left(\mathrm{X}=\mathrm{Cl}^{-}\right.$or $\mathrm{SCN}^{-}$and $\mathrm{L}=\mathrm{Bzmbl}$, Bzebl, Bzpmbl and Bzprbl): About $10 \mathrm{mmol}$ of appropriate ligand was dissolved in $20 \mathrm{~mL}$ hot ethanol and treated with 5 mmol of platinum(II) chloride solution taken from stock solution. The mixed solution was refluxed on a steam bath in flask to get orange yellow solution. The resulting solution on concentration yielded cream yellow product. The product was filtered, washed with aqueous ethanol and dried in a desiccator over $\mathrm{CaCl}_{2}$. The complex $\mathrm{PtL}_{2}(\mathrm{SCN})_{2}$ were prepared by metathesis reaction with $\mathrm{PtL}_{2} \mathrm{Cl}_{2}$ and $\mathrm{KCNS}$.

The electronic absorption spectra of complexes were determined in the range 200-650 $\mathrm{nm}$ and electronic absorption band positions of ligands and thier complexes are shown in Table-B. The I.R spectra of complexes were recorded as $\mathrm{KBr}$ disc in the range $4000-400 \mathrm{~cm}^{-1}$ and the prominent IR bands of some complexes are given in Table- 3 .

\section{RESULTS AND DISCUSSION}

The analytical data of the synthesized complexes of Pd(II) and Pt(II) of substituted steryl benzimidazoles are given in Table-1.

The steryl derivatives of 2-alkylbenzimidazole ( $\mathrm{L}$ ) form bis-ligated complexes $\mathrm{PdL}_{2} \mathrm{Cl}_{2}, \mathrm{PtL}_{2} \mathrm{Cl}_{2}$ as well as $\mathrm{PdL}_{2}(\mathrm{SCN})_{2}$ mono-ligated dichloro or dithiocyanato complexes of composition $\mathrm{PdLCl}_{2}$ and $\mathrm{PdL}(\mathrm{SCN})_{2},(\mathrm{~L}=\mathrm{Bzmbl}$, Bzebl, Bzpmbl or Bzprbl). The complexes dissolved slightly in ethanol and methanol but sparingly soluble in dimethyl formamide. The diluted and freshly prepared DMF solution of complexes show low electrical conductance value $\left(8-15 \mathrm{ohm}^{-1} \mathrm{~mol}^{-1} \mathrm{~cm}^{2}\right)$ at $300-310^{\circ} \mathrm{C}$. The low electrical conductance value of complexes suggested coordinated nature of chloride or thiocyanate group in complexes [14]. As expected, the complexes $\operatorname{PdLX}_{2}\left(\mathrm{X}=\mathrm{Cl}^{-}\right.$ or $\left.\mathrm{SCN}^{-}\right), \mathrm{PtL}_{2} \mathrm{X}_{2}\left(\mathrm{X}=\mathrm{Cl}^{-}\right.$or $\left.\mathrm{NCS}^{-}\right)$and $\mathrm{PdL}_{2} \mathrm{Cl}_{2}$ are diamagnetic and complexes possess four coordinated square planar structure $[15,16]$. However, Pt(II) monoligated complexes PtLX $\mathrm{X}_{2}$ could not be isolated.

The electronic absorption spectra of complexes were recorded in ethanol in the range $200-650 \mathrm{~nm}$ and prominent band positions are shown in Table-2. In ultraviolet region these ligands show two bands near 212 and $268 \mathrm{~nm}$ for Bzmbl and these are assigned as $\sigma \rightarrow \sigma^{*}$ and $\pi \rightarrow \pi^{*}$ transition. These transitions are observed in other steryl derivatives between 205-214 $\mathrm{nm}$ and $265-272 \mathrm{~nm}$. The $\pi \rightarrow \pi^{*}$ transition of ligand is shifted to lower wavenumber in complexes on complexation [17]. The complexes show strong absorption below 300-320 $\mathrm{nm}$ probably charge transfer transition [16,17]. Palladium(II) and platinum(II) have $\mathrm{n} d^{8}$ electronic system and in planar complexes with $d s p^{2}$ hybrid bonding which generates ${ }^{1} \mathrm{~A}_{1 \mathrm{~g}}$ as the ground state. The $\operatorname{Pt}(\mathrm{II})$ and $\mathrm{Pd}(\mathrm{II})$ complexes in planar field can show ${ }^{1} \mathrm{~A}_{1 \mathrm{~g}} \rightarrow{ }^{1} \mathrm{~B}_{\mathrm{lg}},{ }^{1} \mathrm{~A}_{1 \mathrm{~g}} \rightarrow{ }^{1} \mathrm{~A}_{2 \mathrm{~g}}$ transition in visible region and other transition will shift to ultraviolet region. The $\mathrm{Pd}(\mathrm{II})$ complexes show a medium band in the region 445-455 $\mathrm{nm}$ (Table-2) assigned as ${ }^{1} \mathrm{~A}_{\mathrm{lg}} \rightarrow{ }^{1} \mathrm{~A}_{2 \mathrm{~g}}$ transition in square planar field. Platinum (II) complexes show ligand field transition in ultraviolet region. The electronic absorption band near 285$290 \mathrm{~nm}$ for Pt(II) complexes is assigned to $\pi \rightarrow \pi^{*}$ transition. The complexes $\left[\mathrm{Pt}(\mathrm{Bzmbl})_{2} \mathrm{Cl}_{2}\right]$ shows a medium band in visible at $415 \mathrm{~nm}$ and $\mathrm{Pt}(\mathrm{Bzebl})_{2} \mathrm{Cl}_{2}$ display a shoulder at $421 \mathrm{~nm}$ (Table-2) assigned as ${ }^{1} \mathrm{~A}_{1 \mathrm{~g}} \rightarrow{ }^{1} \mathrm{~A}_{2 \mathrm{~g}}$ transition in four coordinated square planar field [17].

The IR spectra of steryl derivatives and their Pd(II) and $\mathrm{Pt}(\mathrm{II})$ complexes showed a characteristic IR vibration of steryl bond $(\mathrm{HC}=\mathrm{CH})$ stretching vibrations in the range 1658-1624 $\mathrm{cm}^{-1}$ in free ligands and their complexes $\mathrm{PdLCl}_{2}$ and $\mathrm{PtL}_{2} \mathrm{Cl}_{2}$. The ligand [(1H-benzimidazol-2-yl)methylbenzylidene] shows benzimidazole ring $\mathrm{NH}$ stretch at $3197 \mathrm{~cm}^{-1}$ and phenyl ring $v(\mathrm{C}-\mathrm{H})$ and steryl group $v(\mathrm{C}-\mathrm{H})$ between $3120-2973 \mathrm{~cm}^{-1}$ and

TABLE-1

ANALYTICAL DATA OF Pd(II) AND Pt(II) COMPLEXES OF SUBSTITUTED STERYL BENZIMIDAZOLE

\begin{tabular}{|c|c|c|c|c|c|c|}
\hline \multirow{2}{*}{ Complexes } & \multicolumn{5}{|c|}{ Elemental analysis (\%): Found (calcd.) } & \multirow{2}{*}{$\begin{array}{l}\Omega^{-1} \text { molar } \\
\text { conductance }\end{array}$} \\
\hline & M & $\mathrm{N}$ & $\mathrm{C}$ & $\mathrm{H}$ & $\mathrm{Cl}$ & \\
\hline$\left[\mathrm{Pd}(\mathrm{Bzmbl}) \mathrm{Cl}_{2}\right.$ & $26.61(26.80)$ & $6.89(7.04)$ & $45.13(45.29)$ & $3.21(3.02)$ & $17.71(17.87)$ & 10 \\
\hline$\left[\mathrm{Pd}(\mathrm{Bzmbl})(\mathrm{NCS})_{2}\right]$ & $23.91(24.05)$ & $12.73(12.66)$ & $46.21(46.11)$ & $3.10(2.71)$ & - & 7 \\
\hline$\left[\mathrm{Pd}(\mathrm{Bzebl}) \mathrm{Cl}_{2}\right]$ & $25.71(25.86$ & $6.51(6.81)$ & $46.51(46.67)$ & $3.45(3.40)$ & $17.31(17.26)$ & 8 \\
\hline$\left[\mathrm{Pd}(\mathrm{Bzebl})(\mathrm{NCS})_{2}\right]$ & $23.11(23.31)$ & $12.01(12.27)$ & $47.21(47.33)$ & $3.21(3.07)$ & - & 10 \\
\hline$\left[\mathrm{Pd}(\mathrm{Bzpmbl}) \mathrm{Cl}_{2}\right]$ & $22.19(22.45)$ & $5.79(5.91)$ & $53.13(53.23)$ & $3.41(3.38)$ & $14.69(14.98)$ & 9 \\
\hline$\left[\mathrm{Pd}(\mathrm{Bzpmbl})(\mathrm{NCS})_{2}\right]$ & $20.41(20.52)$ & $10.92(10.80)$ & $53.13(53.24)$ & $3.12(3.09)$ & - & 6 \\
\hline$\left[\mathrm{Pd}(\mathrm{Bzprbl})(\mathrm{NCS})_{2}\right]$ & $22.74(22.62)$ & $11.79(11.90)$ & $48.31(48.47)$ & $3.51(3.40)$ & - & 6 \\
\hline$\left[\mathrm{Pd}(\mathrm{Bzprbl}) \mathrm{Cl}_{2}\right]$ & $25.11(25.01)$ & $6.51(6.58)$ & $47.79(47.95)$ & $3.81(3.76)$ & $16.73(16.69)$ & 14 \\
\hline$\left[\mathrm{Pt}(\mathrm{Bzmbl})_{2} \mathrm{Cl}_{2}\right]$ & $27.53(27.62)$ & $7.88(7.93)$ & $50.83(50.99)$ & $3.51(3.40)$ & $10.11(10.06)$ & 15 \\
\hline$\left[\mathrm{Pt}(\mathrm{Bzebl})_{2} \mathrm{Cl}_{2}\right]$ & $26.41(26.57)$ & $7.49(7.63)$ & $52.37(52.32)$ & $3.92(3.81)$ & $9.78(9.67)$ & 12 \\
\hline$\left[\mathrm{Pt}(\mathrm{Bzpmbl})_{2} \mathrm{Cl}_{2}\right]$ & $22.81(22.73)$ & $16.59(16.53)$ & $58.63(58.74)$ & $3.89(3.73)$ & $8.11(8.27)$ & 11 \\
\hline$\left[\mathrm{Pt}(\mathrm{Bzprbl}){ }_{2} \mathrm{Cl}_{2}\right]$ & $25.41(25.59)$ & $7.46(7.35)$ & $53.31(53.54)$ & $4.10(4.20)$ & $9.41(9.32)$ & 12 \\
\hline$\left[\mathrm{Pt}(\mathrm{Bzmbl})_{2}(\mathrm{NCS})_{2}\right]$ & $25.83(26.01)$ & $11.01(11.18)$ & $50.91(51.13)$ & $3.31(3.19)$ & - & 13 \\
\hline$\left[\mathrm{Pt}(\mathrm{Bzebt})_{2}(\mathrm{NCS})_{2}\right.$ & $25.01(25.08)$ & $10.61(10.78)$ & $51.84(52.37)$ & $3.68(3.59$ & - & 10 \\
\hline
\end{tabular}




\begin{tabular}{ll}
\hline & \multicolumn{1}{c}{ TABLE-2 } \\
\multicolumn{1}{c}{ ELECTRONIC ABSORPTION BAND POSITION OF } \\
\multicolumn{1}{c}{ LIGAND AND SOME COMPLEXES (nm) }
\end{tabular}

these vibrations are retained with slight change in band positions and intensity in complexes. The $\mathrm{v}(\mathrm{C}=\mathrm{C})$ stretching band was observed at $1642 \mathrm{~cm}^{-1}$ which is retained in $\mathrm{Pt}(\mathrm{II})$ complexes $\mathrm{PtL}_{2} \mathrm{Cl}_{2}$ but shifted to lower frequency by $20-30 \mathrm{~cm}^{-1}$ in $\mathrm{PdLCl}_{2}$ suggesting involvement of $\mathrm{C}=\mathrm{C}$ double bond in coordinate bond formation. The $v(\mathrm{C}=\mathrm{N})$ of benzimidazole ring was located at $1595 \mathrm{~cm}^{-1}$ is shifted by $15-10 \mathrm{~cm}^{-1}$ to lower frequency in complexes, supporting coordination of benzimidazole pyridine nitrogen in bond formation. The benzimidazole $(\mathrm{NH})$ bending band is observed at $1520 \mathrm{~cm}^{-1}$ which is retained in almost all complexes indicating that it is not the bonding site of ligand in $\mathrm{Pd}(\mathrm{II})$ or $\mathrm{Pt}(\mathrm{II})$ complexes. The $(\mathrm{CH})$ out of plane bending band of 2-steryl benzimidazole is located at $745 \mathrm{~cm}^{-1}$ as strong band in free ligand and in metal complexes [18]. The key IR bands of different steryl derivatives and their representative complexes are given in Table-3.

The IR spectrum of benzylidene derivative of 2-ethylbenzimidazole (Bzebl) shows $v(\mathrm{NH})$ benzimidazole ring at 3215 $\mathrm{cm}^{-1}$ and $(\mathrm{C}-\mathrm{H})$ stretch of steryl group at $3135 \mathrm{~cm}^{-1}$ and these vibrations are retained in complexes. The $v(C=C)$ vibration of steryl group was located at $1652 \mathrm{~cm}^{-1}$ and $v(\mathrm{C}=\mathrm{N})$ at 1605 $\mathrm{cm}^{-1}$. The $v(\mathrm{C}=\mathrm{C})$ and $v(\mathrm{C}=\mathrm{N})$ of ligand shifted to lower frequency in $\mathrm{PdLCl}_{2}$ indicating the coordination of both $(\mathrm{C}=\mathrm{C}) \pi$ electrons and $(\mathrm{C}=\mathrm{N})$ nitrogen with palladium(II). The $v(\mathrm{C}=\mathrm{N})$ of ligands are shifted to lower wave number in bisligated complexes $\mathrm{PdL}_{2} \mathrm{Cl}_{2}$ and $\mathrm{PtL}_{2} \mathrm{Cl}_{2}$, but steryl (-C=C) stretch remains unaffected sugges- ting monodentate bonding through $(\mathrm{C}=\mathrm{N})$ nitrogen of ligand [19]. The free ligand and its complexes show a number of IR bands in finger print region due to various mode of IR vibration of phenyl and benzimidazole ring. The thiocyanato complex $\mathrm{Pd}(\mathrm{Bzmbl})(\mathrm{SCN})_{2}$ shows a sharp and strong band at $2105 \mathrm{~cm}^{-1}$ due to $v(\mathrm{C}=\mathrm{N})$ and a medium $v(\mathrm{C}=\mathrm{S})$ vibration at $725 \mathrm{~cm}^{-1}$ indicating coordination of thiocyanate group through sulphur atom in dithiocyanato complexes [18]. Thus, from IR spectra, it is concluded that in $\mathrm{PdLCl}_{2}$ type of complexes, steryl group double bond $\left(\mathrm{CH}=\mathrm{CH}-\mathrm{C}_{6} \mathrm{H}_{5}\right)$ appears to be coordinated and the ligand is bidentate in which and second donor site is benzimidazole ring pyridine nitrogen. In case of $\mathrm{PtL}_{2} \mathrm{Cl}_{2}$, the ligands are $\mathrm{N}$ donor mono-coordinated unidentate molecule. The probable structures of complexes are shown below:

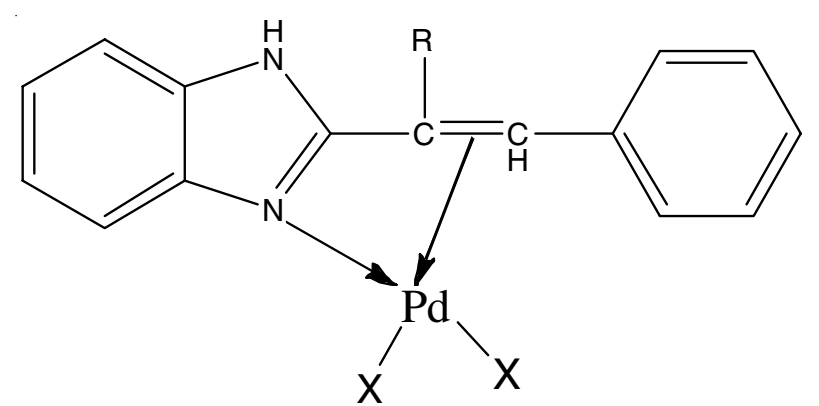

Structure of $\mathrm{PdLX}_{2}\left(\mathrm{X}=\mathrm{Cl}^{-}\right.$or $\left.\mathrm{SCN}^{-}\right)\left(\mathrm{R}=\mathrm{H},-\mathrm{CH}_{3}\right),-\mathrm{CH}_{2}-\mathrm{CH}_{3}$ and $\left.\mathrm{C}_{6} \mathrm{H}_{5}\right)$

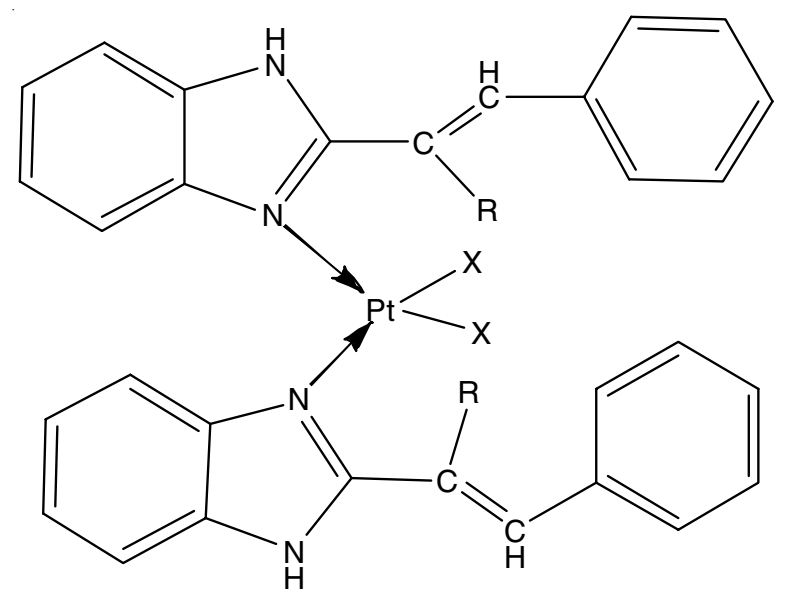

Structure of $\mathrm{PtL}_{2} \mathrm{X}_{2}\left(\mathrm{X}=\mathrm{Cl}^{-}\right.$or $\left.\mathrm{SCN}^{-}\right)\left(\mathrm{R}=\mathrm{H},-\mathrm{CH}_{3}\right),-\mathrm{CH}_{2}-\mathrm{CH}_{3}$ and $\left.\mathrm{C}_{6} \mathrm{H}_{5}\right)$

TABLE-3

KEY IR BANDS $\left(\mathrm{cm}^{-1}\right)$ OF Pd(II) AND Pt(II) COMPLEXES OF SUBSTITUTED STERYL BENZIMIDAZOLE

\begin{tabular}{|c|c|c|c|c|c|c|c|}
\hline Compound & $v(\mathrm{NH})$ & $v(\mathrm{C}-\mathrm{H})$ & $v(C=C)$ steryl & $v(\mathrm{C}=\mathrm{N})$ & $\delta(\mathrm{N}-\mathrm{H})$ & $\begin{array}{l}\text { Out-of-plane } \\
\text { (C-H) phenyl }\end{array}$ & $\begin{array}{c}\text { Ring } \\
\text { deformation }\end{array}$ \\
\hline Bzmbl & 3197 & 3120 & 1642 & 1595 & 1520 & 745 & 680,540 \\
\hline $\mathrm{Pd}(\mathrm{Bzmbl}) \mathrm{Cl}_{2}$ & 3220 & 3156 & 1626 & 1590 & 1520 & 742 & 670,526 \\
\hline $\mathrm{Pt}(\mathrm{Bzmbl})_{2} \mathrm{Cl}_{2}$ & 3207 & 3150 & 1643 & 1590 & 1504 & 748 & 665,527 \\
\hline Bzprbl & 3312 & 3170 & 1658 & 1605 & 1512 & 738 & 692,518 \\
\hline $\mathrm{Pd}(\mathrm{Bzprbl}) \mathrm{Cl}_{2}$ & 3300 & 3168 & 1630 & 1590 & 1508 & 738 & 691,525 \\
\hline $\mathrm{Pt}(\text { Bzprbl })_{2} \mathrm{Cl}_{2}$ & 3290 & 3150 & 1655 & 1595 & 1507 & 742 & 685,525 \\
\hline Bzpmbl & 3245 & 3140 & 1655 & 1605 & 1498 & 748 & 668,527 \\
\hline $\mathrm{Pd}(\mathrm{Bzpmbl}) \mathrm{Cl}_{2}$ & 3240 & 3130 & 1621 & 1592 & 1488 & 745 & 670,527 \\
\hline $\mathrm{Pt}(\mathrm{Bzpmbl})_{2} \mathrm{Cl}_{2}$ & 3247 & 3150 & 1653 & 1585 & 1490 & 742 & 670,527 \\
\hline Bzebl & 3272 & 3162 & 1662 & 1610 & 1507 & 738 & 675,538 \\
\hline $\mathrm{Pd}(\mathrm{Bzebl}) \mathrm{Cl}_{2}$ & 3268 & 3152 & 1628 & 1590 & 1512 & 735 & 670,530 \\
\hline $\mathrm{Pt}(\mathrm{Bzebl})_{2} \mathrm{Cl}_{2}$ & 3270 & 3148 & 1665 & 1595 & 1510 & 740 & 672,540 \\
\hline
\end{tabular}




\section{REFERENCES}

1. Y. Qi, F. Luo, S. R. Batten, Y. X. Che and J. M. Zheng, Crystal Growth Design, 8, 2806 (2008); https://doi.org/10.1021/cg701061q

2. Y.Q. Lan, S.L. Li, J.S. Qin, D.Y. Du, X.L. Wang, Z.M. Su and Q. Fu, Inorg. Chem., 47, 10600 (2008); https://doi.org/10.1021/ic801275w.

3. Z.-X. Li, T.-L. Hu, H. Ma, Y.-F. Zeng, C.J. Li, M.-L. Tong and X.H. Bu, Crystal Growth Design, 10, 1138 (2010); https://doi.org/10.1021/cg900980y.

4. J.Q. Chen, Y.P. Cai, H.C. Fang, Z.-Y. Zhou, X.-L. Zhan, G. Zhao and Z. Zhang, Crystal Growth Design, 9, 1605 (2009); https://doi.org/10.1021/cg8013317.

5. K. Vera, H. Veronika, S. Petra, K. Katerina, C. Kristýna and S. Lenka, Anti-Cancer Drugs, 24, 911 (2013); https://doi.org/10.1097/CAD.0b013e3283648c69.

6. P. Kopel, D. Wawrzak, V. Langer, K. Cihalova, D. Chudobova, R. Vesely, V. Adam and R. Kizek, Molecules, 20, 10360 (2015); https://doi.org/10.3390/molecules200610360.

7. S.P. Ghosh and L.K. Mishra, Inorg. Chim. Acta, 7, 545 (1973); https://doi.org/10.1016/S0020-1693(00)94881-3.

8. F. Téllez, H. López-Sandoval, S.E. Castillo-Blum and N. BarbaBehrens, ARKIVOC, 245 (2008); https://doi.org/10.3998/ark.5550190.0009.519.
9. R.C. Rocha, F.N. Rein and H.E. Toma, J. Braz. Chem. Soc., 12, 234 (2001); https://doi.org/10.1590/S0103-50532001000200018.

10. T. Yutaka, S. Obara, S. Ogawa, K. Nozaki, N. Ikeda, T. Ohno, Y. Ishii, K. Sakai and M. Haga, Inorg. Chem., 44, 4737 (2005); https://doi.org/10.1021/ic048622z.

11. S. Rekha and K.R. Nagasundara, Indian J. Chem., 44A, 2421 (2005).

12. R, Yang, H.H. Li, K. Van Hecke and G.H. Cui, Z. Anorg. Allg. Chem., 641, 642 (2015); https://doi.org/10.1002/zaac.201400464.

13. L.K. Mishra and M. Bala, Int. J. Pharm. Sci. Res., 4, 3620 (2013).

14. W.J. Geary, Coord. Chem. Rev., 7, 81 (1971); https://doi.org/10.1016/S0010-8545(00)80009-0.

15. R.S. Nyholm and B.N. Figgis, Prog. Inorg. Chem., 6, 37 (1966)

16. E. König, Struct. Bonding, 9, 175 (1971); https://doi.org/10.1007/BFb0118887.

17. A.B.P, Lever, Inorganic Electronic Spectroscopy, Elsevier, Amsterdam pp. 288-375 (1968)

18. K. Nakamoto, Infrared and Raman Spectra of Inorganic and Complex Compounds, John Wiley, New York (1978).

19. L.J. Bellamy, The Infrared Spectra of Complex Molecule, Chapman and Hall, London, edn 2 (1980) 